\title{
A Cooperative Taxonomic Study of Mycobacteria Isolated from Armadillos Infected with Mycobacterium leprae
}

\author{
By F. PORTAELS,${ }^{1}$ C C. ASSELINEAU, ${ }^{2}$ I. BAESS,${ }^{3}$ M. DAFFÉ, ${ }^{2}$ \\ G. DOBSON, ${ }^{4}$ P. DRAPER, ${ }^{5}$ D. GREGORY, ${ }^{5}$ R. M. HALL,${ }^{6} \dagger$ \\ T. IMAEDA, ${ }^{7}$ P. A. JENKINS, ${ }^{8}$ M. A. LANÉLLE, ${ }^{2}$ L. LARSSON, ${ }^{9}$ \\ M. MAGNUSSON,${ }^{3}$ D. E. MINNIKIN, ${ }^{4}$ S. R. PATTYN,${ }^{1}$ G. WIETEN ${ }^{10}$ \\ AND P. R. WHEELER 6 \\ ${ }^{1}$ Department of Microbiology, Institute of Tropical Medicine, Nationalestraat 155, \\ B-2018 Antwerp, Belgium \\ ${ }^{2}$ Centre de Recherche de Biochimie et Génétique Cellulaires du CNRS, Université Paul Sabatier, \\ F-31062 Toulouse, France \\ ${ }^{3}$ Tuberculosis Department, Statens Seruminstitut, DK-2300 Copenhagen, Denmark \\ ${ }^{4}$ School of Chemistry, The University, Newcastle upon Tyne NE1 7RU, UK \\ ${ }^{5}$ National Institute for Medical Research, Mill Hill, London NW7 1AA, UK \\ ${ }^{6}$ Department of Biochemistry, University of Hull, Hull HU6 $7 R X, U K$ \\ ${ }^{7}$ University of Medicine and Dentistry of New Jersey, New Jersey Medical School, Newark, \\ NJ 07103, USA \\ ${ }^{8}$ Public Health Laboratory, University Hospital of Wales, Cardiff CF4 $4 X W, U K$ \\ ${ }^{9}$ Department of Medical Microbiology, University of Lund, Lund, Sweden \\ ${ }^{10}$ FOM Institute for Atomic and Molecular Physics, 1098SJ Amsterdam, The Netherlands
}

(Received 27 February 1986; revised 11 June 1986)

Seventeen strains of mycobacteria, recovered from six armadillos experimentally infected with Mycobacterium leprae, were examined in ten different laboratories. This collaborative study included use of conventional bacteriological tests, lipid analyses, determination of mycobactins and peptidoglycans, characterization by Py-MS, and immunological, metabolic, pathological and DNA studies. These armadillo-derived mycobacteria (ADM) formed five homogeneous groups (numbered ADM 1 to 5) on the basis of phenetic analyses. However, DNA studies revealed only four homogeneous groups since group ADM 1 and one of the two strains in group ADM 3 showed a high level of DNA relatedness. The phenetic and DNA studies confirmed that the ADM strains differed from all other known mycobacteria. Cultural, biochemical, metabolic and pathogenic properties as well as DNA-DNA hybridizations clearly differentiated these ADM from $M$. leprae.

\section{INTRODUCTION}

In 1982, mycobacteria phenotypically distinct from all the presently known species were isolated from the livers of two armadillos which had been experimentally infected with Mycobacterium leprae (Portaels et al., 1982). Subsequently, other novel mycobacteria have been recovered from $M$. leprae-infected armadillos (Portaels et al., 1985). These armadillo-derived mycobacteria (ADM) did not fit into the established classification of Jenkins et al. (1982) and were temporarily assigned to three new groups: ADM 1, ADM 2 and ADM 3 (Portaels et al.,

† Present address: Glaxo Group Research Ltd, Greenford UB6 0HE, UK.

Abbreviations: ADM, armadillo-derived mycobacteria; CRIS testing, comparative reciprocal intradermal sensitin testing; DAP, diaminopimelic acid; MAIS complex, M. avium-intracellulare-scrofulaceum complex. 
1985). A collaborative study using conventional tests, analysis of lipids, mycobactins and peptidoglycans, characterization by Py-MS, immunology, metabolism, pathogenicity, and DNA-DNA hybridization was undertaken for two main purposes: (1) to clarify the taxonomic status of these ADM and establish their degree of relationship with other mycobacterial species ( $M$. leprae included); and (2) to find specific markers in these ADM that might eventually permit their differentiation from $M$. leprae. The results of this study are presented here.

\section{METHODS}

Bacterial strains. Strains were isolated according to Portaels et al. $(1982,1985)$ and streaked onto Dubos Oleic Agar for purity. Seventeen strains were obtained, and included in the present study (Table 1). Not all the strains were analysed by all the laboratories; in certain cases, representative strains of the ADM groups were chosen.

Characterization of the ADM. The 17 strains were identified as described by Jenkins et al. (1982). The $\mathrm{pH}$ range for growth was determined after Portaels \& Pattyn (1982) and Portaels et al. (1982). The pyridine extractability of acid fastness was tested by the method of Convit \& Pinardi (1972). Growth on media containing glucose as sole carbon source and nicotinamide as sole nitrogen source was carried out as described by Tsukamura \& Tsukamura (1966).

Lipid analyses. The lipids of all but three strains (i.e. 8837, 8968 and 9091) plus reference cultures were examined by TLC according to Jenkins (1980). This technique did not need any transformation of the native lipids. By using specific reagents (and reference lipid samples), unusual types of lipids were characterized on thin-layer chromatograms of the complex lipids extracted from six strains $(8251,8480,8507,8561,8637$ and 9091) using the methods of Portaels et al. (1984).

TLC analysis of methyl mycolates required their isolation from complex derivatives (trehalose esters, derivatives of arabinogalactan or of glycerol, or of long-chain secondary alcohols) which occurred in the bacteria. Different methods were used, i.e. acid or alkaline methanolysis (Minnikin \& Goodfellow, 1980; Minnikin et al., $1984 a$ ) or alkaline hydrolysis followed by methylation (Daffe et al., 1983) of the whole cells. These methods gave similar results when applied to the same strain; therefore results concerning mycolate composition are presented as a whole.

The long-chain secondary alcohols (2-octadecanol, 2-eicosanol), which are always present along with the dicarboxymycolates, were characterized either by TLC (during the analysis of methyl mycolates), or by GC as described by Larsson et al. (1985).

Lipid profiles were also obtained by Py-GC, as described by Wieten et al. (1984). Pyrolysis yields various lipid compounds, including octadecene isomers and eicosene isomers from the esters of long-chain alcohols with dicarboxymycolic acids (wax esters). Py-GC was performed on nine strains $(8480,8483,8507,8560,8563,8608$, 8634, 8637 and 8668) and a comparison was made with Py-GC profiles of other mycobacteria.

Isolation and characterization of the mycobactins. Seven strains $(8480,8634,8637,8251,8563,8837$ and 8968$)$ were examined for possible mycobactin formation. They were cultivated in liquid glycerol/asparagine medium (Ratledge \& Hall, 1971) and on glycerol/asparagine medium solidified with $2 \%$ (w/v) Lab M agar (London Analytical and Bacteriological Media) (Hall \& Ratledge, 1982).

Where mycobactin was formed (as demonstrated by apple-green fluorescence of cells under UV light), bacteria were scraped from solidified medium or harvested by centrifugation $(10000 \mathrm{~g}$ for $10 \mathrm{~min})$ from liquid medium. Cell-bound mycobactin was extracted in the usual way using ethanol, with final yields determined as described by Hall \& Ratledge (1982).

TLC analysis of mycobactin was done in a single dimension, with a range of adsorbents and solvents (Hall \& Ratledge, 1984): system I, silica gel G, $20 \times 20 \mathrm{~cm}$ (Analtech), developed with petroleum spirit/ethyl acetate/nbutanol $(2: 3: 3$, by vol.); system II, kieselgel $60,10 \times 20 \mathrm{~cm}$ with a $2.5 \times 10 \mathrm{~cm}$ concentrating zone (Merck/BDH), developed as for system I; system III, high performance thin-layer plates $10 \times 10 \mathrm{~cm}$ with a $2.5 \times 10 \mathrm{~cm}$ concentrating zone (Merck/BDH), developed as for system I; system IV, alumina GF, $20 \times 20 \mathrm{~cm}$ (Analtech), developed with cyclohexane/n-butanol $(9: 1, \mathrm{v} / \mathrm{v})$; system $\mathrm{V}$, plates as for system I but using propan2-ol as solvent.

Peptidoglycan analyses. Wet, 'fixed' cells from four strains $(8251,8507,8511$ and 8480$)$ were dried in vacuo over $\mathrm{NaOH}$. Dried cells were extracted twice for $24 \mathrm{~h}$ with ethanol/diethyl ether $(1: 1, \mathrm{v} / \mathrm{v})$, then dried. Cells (about $100 \mathrm{mg}$ of each strain) were broken in $5 \mathrm{ml}$ saline for $20 \mathrm{~min}$, using a Dawe Soniprobe ultrasonic generator operating at $80 \mathrm{~W}$. The suspensions were contained in a thin stainless-steel tube cooled in ice-water. Unbroken cells were collected by centrifugation at $3000 \mathrm{~g}$ for $10 \mathrm{~min}$, then the walls were collected by centrifugation at $27000 \mathrm{~g}$ for $1 \mathrm{~h}$. Walls were suspended in $5 \mathrm{ml} 0.1 \mathrm{M}$-HEPES buffer, $\mathrm{pH} 7 \cdot 5$, containing $1 \mathrm{mM}-\mathrm{Mg}^{2+}, 0 \cdot 2 \%(\mathrm{w} / \mathrm{v})$ sodium azide, RNAase $\left(100 \mu \mathrm{g} \mathrm{ml}^{-1}\right.$ ) and DNAase type I (about $50 \mu \mathrm{g} \mathrm{ml}^{-1}$ ) and incubated at $37^{\circ} \mathrm{C}$ for $24 \mathrm{~h}$. Trypsin and chymotrypsin (each about $100 \mu \mathrm{g} \mathrm{ml}^{-1}$ ) were then added and incubation was continued for a further $24 \mathrm{~h}$. Walls were collected by centrifugation at $27000 \mathrm{~g}$ for $1 \mathrm{~h}$, suspended in $1 \%(\mathrm{w} / \mathrm{v}) \mathrm{SDS}$ at room temperature 
Table 1. Source of the 17 test strains isolated from armadillos

\begin{tabular}{llcl}
\multicolumn{1}{c}{ Strain no. } & Source* & Armadillo no. & Tissue \\
9091 & AFIP & 5 & liver \\
$8251,8346,8480,8483,8637$ & IP & AJ & liver \\
$8507,8511,8560,8561,8563,8608,8698$ & NIMR & $2457 / 10$ & liver \\
8634,8668 & CDC & 44 & liver \\
8968 & MRI & A49 & spleen \\
8837 & MRI & A20 & spleen
\end{tabular}

* AFIP, Armed Forces Institute of Pathology, Washington (Dr G. P. Walsh); IP, Institut Pasteur, Cayenne (Dr Y. Robin); NIMR, National Institute for Medical Research, London (Dr R. J. W. Rees); CDC, Center for Disease Control, Atlanta (Dr C. C. Shepard); MRI, Medical Research Institute, Melbourne (Drs E. E. Storrs \& A. M. Dhople).

for $24 \mathrm{~h}$, sequentially washed with water, $1 \mathrm{M}-\mathrm{NaCl}$ and water, and finally freeze-dried. Yields for the four strains were between 1 and $2 \%$ of the original bacterial suspension.

Walls were hydrolysed in sealed tubes with $4 \mathrm{M}-\mathrm{HCl}$ at $105^{\circ} \mathrm{C}$ for $16 \mathrm{~h}(0.5 \mathrm{ml}$ acid, $1-2 \mathrm{mg}$ walls $)$. The hydrolysates were filtered through Whatman no. 50 paper to remove lipids, then evaporated over $\mathrm{NaOH}$ in vacuo and submitted to automatic amino acid analysis.

Characterization by $P$ - $M S$. Curie-point pyrolysis coupled on-line to low-resolution mass spectrometry was used to analyse intact cells from nine strains $(8480,8483,8560,8507,8563,8608,8634,8637$ and 8668). Py-MS instrumentation and analysis conditions were as described by Wieten et al. (1983). The taxonomic and chemical relationships among the strains were deduced from the Py-MS data by discriminant analysis (Wieten et al., 1983) using the Arthur data handling package, as modified by Hoogerbrugge et al. (1983).

Comparative reciprocal intradermal sensitin (CRIS) testing. The ADM strains $(8251,8346,8563$ and 8608$)$ and reference strains tested are listed in Table 5. The experimental procedure was as described previously (Magnusson, 1961, 1971; Magnusson \& Mariat, 1968). The data presented here were drawn from a series of 12 studies, comprising a total of 92 guinea-pigs. Male albino guinea-pigs (strain Ssc: A1), each weighing 300-350 g, were obtained from the breeding farm 'Hvidesten', Statens Seruminstitut, Copenhagen.

The immunogens of the ADM strains consisted of heat-killed culture filtrates, emulsified in incomplete Freund's adjuvant. The other strains were injected as suspensions of dried, heat-killed culture $\left(0 \cdot 4 \mathrm{mg} \mathrm{ml}^{-1}\right)$ in light paraffin oil (Marcol 52). The sensitins used for eliciting skin reactions in the guinea-pigs were heat-sterilized culture filtrates diluted 1:5 and 1:50 (MNC 461, MNC 579, ADM strains), or 1:50 and 1:500 (MNC 545), or purified preparations produced by similar methods as used for tuberculin PPD (Magnusson, 1961). The doses of the latter preparations were $0.2 \mu \mathrm{g}$ and $2 \mu \mathrm{g}$. The diluent for the sensitins was PBS (10 mM-phosphate buffer, $0.85 \%$ saline, $\mathrm{pH} 7.2)$ with $0.01 \%(\mathrm{w} / \mathrm{v})$ Chinosol and $0.005 \%(\mathrm{w} / \mathrm{v})$ Tween 80 . The results of the skin tests were evaluated by calculating the specificity differences of pairs of sensitins (Magnusson, 1961). The differences are indicated in $\mathrm{mm}$. Each value is the mean difference between eight homologous and eight heterologous reactions.

Metabolic studies. For these studies, ADM strain 8480 was grown in modified Dubos medium. ADM strains 8634, 8251 and 8968 were grown in Middlebrook 7H9 medium except for the experiments involving unbroken ADM, when all were grown in Dubos medium. In all cases, growth was in $25 \mathrm{ml}$ medium contained in $100 \mathrm{ml}$ flasks, which were incubated without shaking for $28 \mathrm{~d}$ at $37^{\circ} \mathrm{C}$. Cell-free extracts were prepared by sonicating, in short bursts, for a total of $11 \mathrm{~min}$ (Wheeler \& Gregory, 1980).

Malate dehydrogenase (EC 1.1.1.37; L-malate : NAD ${ }^{+}$oxidoreductase) was detected spectrophotometrically and on polyacrylamide gels as described by Wheeler \& Bharadwaj (1983). Catalase (EC 1.11.1.6; hydrogen peroxide : hydrogen peroxide oxidoreductase) and superoxide dismutase (EC 1.15.1.1; superoxide : superoxide oxidoreductase) were detected by the methods described by Wheeler \& Gregory (1980).

Experimental pathogenicity for mice. Seven strains $(8251,8480,8561,8634,8637,8837$ and 9091$)$ were titrated in mouse foot pads as described by Shepard (1960) with $5 \times 10^{3}, 5 \times 10^{2}, 50$ and 5 acid-fast bacilli. The mice were examined at 6,9 and 12 months if the counts did not reach $5 \times 10^{5}$ acid-fast bacilli per mouse foot pad. Mice were also intravenously inoculated with $0.25 \mathrm{ml}$ saline containing $10^{7}$ bacteria. The mice were killed after 2 and 6 months and the livers, spleens, lungs and hearts were examined histologically.

DNA-DNA hybridization. DNA was isolated and purified from seven strains $(8251,8346,8563,8608,8634,8837$ and 8968$)$ as described by Baess (1974). The purified DNA $\left(800 \mu \mathrm{g} \mathrm{ml}^{-1}\right)$ was sheared in a French pressure cell press at $14.06 \mathrm{MPa}$. A molecular mass of $681 \mathrm{kDa}( \pm 5 \%)$ for the double-stranded DNA was obtained. For six strains $(8251,8480,8634,8637,8668$ and 8698$)$ the DNA was isolated and purified by T. Imaeda (Imaeda $e t$ al., 1982).

In the laboratory of one of us (I. Baess), DNA-DNA hybridization was measured optically in a spectrophotometer at a temperature of $T_{\mathrm{m}}-25^{\circ} \mathrm{C}\left(T_{\mathrm{m}}\right.$ : temperature at the midpoint of the thermal denaturation 
curve of the DNA mixture). The concentration of DNA was $40 \mu \mathrm{g} \mathrm{ml}^{-1}$ in $3 \times \mathrm{SSC}(1 \times \mathrm{SSC}$ is $0 \cdot 15 \mathrm{M}$-sodium chloride, $0.015 \mathrm{M}$-trisodium citrate, $\mathrm{pH} 7$ ) and $25 \%$ formamide. The reassociation of two single bacterial DNAs was compared with the hybridization of the mixture of these, and percentage homology derived from the formula of Baess \& Weis Bentzon (1978).

In the other participating laboratory (that of T. Imaeda), the methods used for DNA-DNA hybridization and for determination of $c_{0} t_{1 / 2}$ values were described previously (Athwal et al., 1984; Imaeda, 1985).

\section{RESULTS}

\section{Cultural, physiological and biochemical properties of $A D M$}

The 17 ADM strains studied were all Gram-positive, strongly acid-alcohol fast and grew optimally at $37^{\circ} \mathrm{C}$. They may be regarded as slow-growing scotochromogens which can be divided into five groups on the basis of their mycolic acid content and their cultural, physiological and biochemical properties (Table 2). Since previous studies suggested relationships between some ADM and $M$. avium, $M$. scrofulaceum or $M$. gordonae, Table 2 also contains data on these three slow-growing mycobacteria.

Five strains isolated from two different armadillos (AJ and 44$)$ were classified in the first group (ADM 1), eight strains isolated from two different animals (AJ and 2457/10) in the second group (ADM 2) and two strains from two different animals (AJ and 5) in the third group (ADM 3). Single strains were classified in groups ADM 4 (8837) and ADM 5 (8968). The five ADM groups differed from $M$. avium, $M$. scrofulaceum and $M$. gordonae by at least two of the characters listed in Table 2. Thus, groups ADM 1 and ADM 4 resembled $M$. scrofulaceum but differed by the sensitivity to isoniazid $\left(10 \mu \mathrm{g} \mathrm{ml}^{-1}\right)$ and to hydroxylamine hydrochloride $(250 \mu \mathrm{g}$ $\mathrm{ml}^{-1}$ ). ADM 1 and ADM 4 strains also differed from ADM 2 and ADM 5 strains insofar as they did not hydrolyse Tween 80 , used glucose as sole carbon source, and did not use nicotinamide as sole nitrogen source. Conversely, ADM 2 and ADM 5 strains hydrolysed Tween 80 , did not use glucose as sole carbon source, used nicotinamide as sole nitrogen source and grew poorly on Löwenstein-Jensen medium in subculture, $10^{6}$ organisms representing 1 c.f.u. Optimal pH ranges for growth also differentiated ADM 1 and ADM 4 strains from ADM 2 and ADM 5 strains, the latter having a very narrow optimal $\mathrm{pH}$ range (5.4-5.7 for ADM 2 strains and 5.5-5.7 for the ADM 5 strain 8968).

Many properties distinguished the two ADM 3 strains from the other ADM groups and the species listed in Table 2 . These two strains were particularly difficult to grow in subculture; $10^{6}$ organisms corresponded to 1 c.f.u. on both Ogawa and Löwenstein-Jensen media. They were inhibited by malachite green and only grew on Ogawa medium without malachite green. Addition of $\mathrm{NaCl}(1 \%, \mathrm{w} / \mathrm{v})$ stimulated growth. The acid fastness of the two ADM 3 strains was extracted by treatment with pyridine. The narrow optimal $\mathrm{pH}$ range $(5 \cdot 8-6 \cdot 1)$ also differentiated these two strains from the majority of mycobacterial species. A similar $\mathrm{pH}$ range for growth has been found only for $M$. lepraemurium (Portaels \& Pattyn, 1982).

\section{Lipid analysis}

The strains assigned to group ADM 1 gave rise to a single pink spot at the solvent front following TLC according to Jenkins (1980). In the same conditions, the strains assigned to group ADM 2 produced a dark brown spot in the mid-zone of the chromatogram. The ADM 3 strain tested (8637) had a lipid pattern different from those of the other groups or species.

The investigation of glycolipids according to Portaels et al. (1984) showed the presence of mycoside C-like compounds in one strain of group ADM 1 (8480), in the two strains of group $\operatorname{ADM} 3(8637,9091)$, but not in three strains of group ADM $2(8251,8507,8561)$. However, the latter three strains contained a specific, very polar acidic glycolipid. The glycolipid fractions of the two strains of group ADM 3 exhibited common components (mycosides C), but some more lipophilic glycolipids were observed only in strain 8637 .

According to their mycolate patterns, the ADM strains could be separated into three groups (Table 2). All the strains studied, except the two strains of group ADM 3, appeared to contain $\alpha-$ mycolates, ketomycolates and dicarboxymycolates. Strains 8837 (ADM 4) and 8968 (ADM 5) contained only these three kinds of mycolates, identical to those of the MAIS (M. avium- 


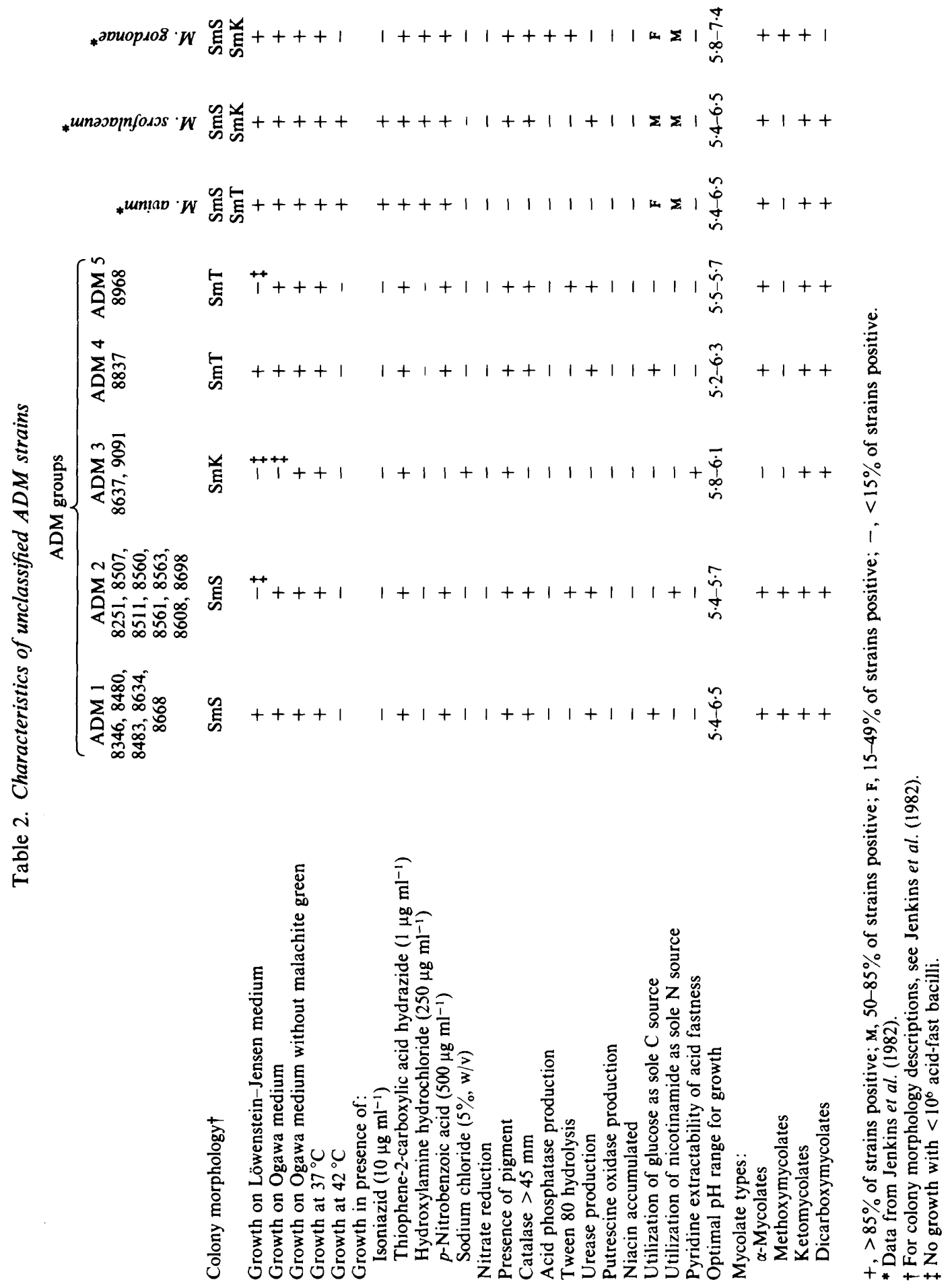


intracellulare-scrofulaceum) complex. Strains assigned to groups ADM 1 and ADM 2 also contained methoxymycolates. The mycolate patterns of the two strains assigned to group ADM 3 were unusual in lacking $\alpha$-mycolate components: only keto- and dicarboxymycolates were observed. However, very small amounts of $\alpha$-mycolates could be detected by preparative TLC and mass spectrometry. The usual conditions of analytical TLC did not allow their detection.

All 17 strains contained long-chain secondary alcohols, identified as mixtures of 2octadecanol and 2-eicosanol by GC of the lipid fractions in the case of three ADM 1 strains $(8346,8480,8634)$, three ADM 2 strains $(8251,8507,8561)$ and the two ADM 3 strains $(8637$, 9091). The presence of these long-chain secondary alcohols in the hydrolysates or methanolysates of mycobacteria containing dicarboxymycolates is a general feature, since in these bacteria these two kinds of compounds are linked by an ester bond.

The presence of dicarboxymycolic acids was also detected in all nine ADM strains (four ADM 1, four ADM 2 and one ADM 3) which were analysed by Py-GC. Highly specific features were observed in the lipid patterns of all ADM pyrograms, which could be identified by Py-GCMS as triplets of isomeric alkenes $\left(\mathrm{C}_{18}-\mathrm{C}_{20}\right)$. The distribution of these alkenes correlated with the distribution of these dicarboxymycolates, from which the alkenes can be readily formed by pyrolysis (Wieten et al., 1984). In all nine strains analysed by Py-GC, tuberculostearic acid was observed.

GC analysis of the products obtained by saponification of the lipids revealed methyl esters of mycocerosic or phthioceranic acids in three strains $(8251,8507,8561)$ of group ADM 2, but not in two strains $(8480,8634)$ of group ADM 1 ; other strains were not examined.

\section{Isolation and characterization of the mycobactins}

Growth of ADM 3 strain 8637 was poor throughout, especially on iron-deficient media, giving insufficient cell yield to allow any mycobactin to be isolated. The other ADM strains grew profusely on the different media tested. The mycobactins isolated from these strains grown on both liquid and solidified glycerol/asparagine medium were analysed by TLC. As found by Hall \& Ratledge (1984), the mycobactins appeared to be identical irrespective of the growth conditions. Previous studies (Portaels et al., 1982, 1985) had already suggested a close relationship of ADM strains 8480,8634 and 8837 to strains belonging to the MAIS complex. Some relationships with $\boldsymbol{M}$. gordonae or $\boldsymbol{M}$. flavescens have also been found for ADM strains 8251,8563 and 8968. Mycobactins isolated from these organisms were therefore compared with those isolated from the ADM strains (Table 3).

ADM 2 strains 8251 and 8563 gave the same typical multi-spot pattern with a four-spot pattern on systems I, II and III. These results clearly differentiated the mycobactins produced by these strains from those of $M$. gordonae (Table 3). Previous examination of the rapidly-growing mycobacteria had shown the mycobactins of $M$. flavescens to be heterogeneous (Hall \& Ratledge, 1984). However, none of the four strains which were examined previously showed much resemblance in their mycobactin patterns to the ADM 2 strains 8251 and 8563 . Mycobactins isolated from the MAIS complex also had different $R_{F}$ values from those of strains 8251 and 8563 .

The ADM 1 strains 8480 and 8634 and ADM 4 strain 8837 produced a spot pattern similar to strains belonging to the MAIS complex. Strain 8968 (ADM 5) produced spot patterns different from all the other ADM strains and from the reference strains mentioned in Table 3.

\section{Peptidoglycan analysis}

The results of the amino acid analyses of walls from some ADM are shown in Table 4. In addition to the amino acids and hexosamines listed, traces of aspartic acid, threonine, serine and leucine were detected $(\leqslant 0 \cdot 1$ molar ratio to DAP).

\section{Characterization by pyrolysis mass spectrometry (Py-MS)}

By discriminant analysis of the total batch of ADM mass spectra, subsets of features (discriminant functions) were obtained which gave insight into the relationships among the 
Table 3. Grouping of ADM strains following TLC of their mycobactins, including an examination of other possibly related mycobacteria

\begin{tabular}{|c|c|c|c|}
\hline \multirow[b]{2}{*}{ Strain* } & \multirow{2}{*}{$\begin{array}{l}\text { ADM } \\
\text { grouping }\end{array}$} & \multicolumn{2}{|c|}{$\begin{array}{c}R_{F} \text { values with } \\
\text { selected TLC systems } \dagger\end{array}$} \\
\hline & & III & V \\
\hline 8480 & 1 & 0.92 & 0.62 \\
\hline 8634 & 1 & 0.92 & 0.62 \\
\hline 8563 & 2 & $0.77,0.72,0.62,0.55$ & $0.60,0.52$ \\
\hline 8251 & 2 & $0.77,0.72,0.61,0.55$ & $0.60,0.54$ \\
\hline 8637 & 3 & \multicolumn{2}{|c|}{ No growth } \\
\hline 8837 & 4 & 0.91 & 0.64 \\
\hline 8968 & 5 & $0.62,0.50$ & 0.60 \\
\hline M. avium AM.1 & - & 0.91 & 0.62 \\
\hline M. intracellulare AM.12 & - & 0.91 & 0.63 \\
\hline M. scrofulaceum AM.22 & - & 0.92 & 0.63 \\
\hline M. gordonae NCTC 10996 & - & 0.86 & $0.60,0.53,0.4 C$ \\
\hline M. flavescens M410 & - & - & 0.53 \\
\hline M. flavescens M411 & - & - & $0.49,0.32$ \\
\hline M. flavescens M413 & - & - & 0.52 \\
\hline M. flavescens M414 & - & - & 0.54 \\
\hline
\end{tabular}

* Cultures prefixed M were kindly supplied by Dr M. Goodfellow, Department of Microbiology, The Medical School, University of Newcastle upon Tyne, UK; cultures prefixed AM were kindly supplied by $\mathrm{Dr}$ A. MacDiamid, Institute for Animal Diseases, Compton, Berkshire, UK.

$\dagger$ See Methods for details of TLC systems III and V. Where more than one $R_{F}$ value is given, multiple spots were detected.

Table 4. Amino acid and hexosamine composition of walls of ADM strains

Composition is expressed as molar ratio relative to diaminopimelic acid (DAP). Figures in parentheses are the actual amounts of DAP found, in $\mathrm{nmol} \mathrm{mg}^{-1}$.

$\begin{array}{lcccc} & \begin{array}{c}8251 \\ \text { (ADM 2) }\end{array} & \begin{array}{c}8507 \\ \text { (ADM 2) }\end{array} & \begin{array}{c}8511 \\ \text { (ADM 2) }\end{array} & \begin{array}{c}8480 \\ \text { (ADM 1) }\end{array} \\ \text { Glucosamine } & 0.69 & 0.71 & 0.68 & 0.78 \\ \text { Ammonia } & 1.27 & 1.23 & 1.76 & 1.35 \\ \text { Muramic acid } & 0.61 & 0.62 & 0.59 & 0.63 \\ \text { Glutamic acid } & 1.13 & 1.12 & 2.02 & 1.10 \\ \text { Glycine } & 0.24 & 0.25 & 0.24 & 0.21 \\ \text { Alanine } & 1.47 & 1.59 & 1.58 & 1.64 \\ \text { DAP } & 1(161) & 1(182) & 1(149) & 1(148)\end{array}$

strains. Of the four discriminant functions (D1, D2, D3 and D4) that were found to be statistically significant, D1 accounted for $87.3 \%$ of the total relevant variance (i.e. that proportion of the total variance in the data set that is meaningful in differentiating between strains). Relative to Dl, strains from groups ADM 1 and ADM 3 formed a tight cluster and group ADM 2 strains another cluster, well separated from the former; strain 8507 was intermediate (Fig. 1). On the remaining discriminant functions (D2, D3, and D4), some heterogeneity was apparent among strains of group ADM 2 . Among the subset of features that are represented by D1, sulphur-containing fragments were prominent, indicating an important role for sulphur components in differentiating the observed subgroups.

The Py-MS spectra from two strains of $M$. gordonae and one strain of $M$. scrofulaceum were added to the ADM data set to show the relationships between these two species and ADM; for this purpose new discriminant functions were calculated. On each individual (new) discriminant function D1, D2 and D3, a relationship between ADM, M. gordonae and $M$. scrofulaceum was observed, whereas on D4, ADM were separated clearly from the latter two species. Notably, 


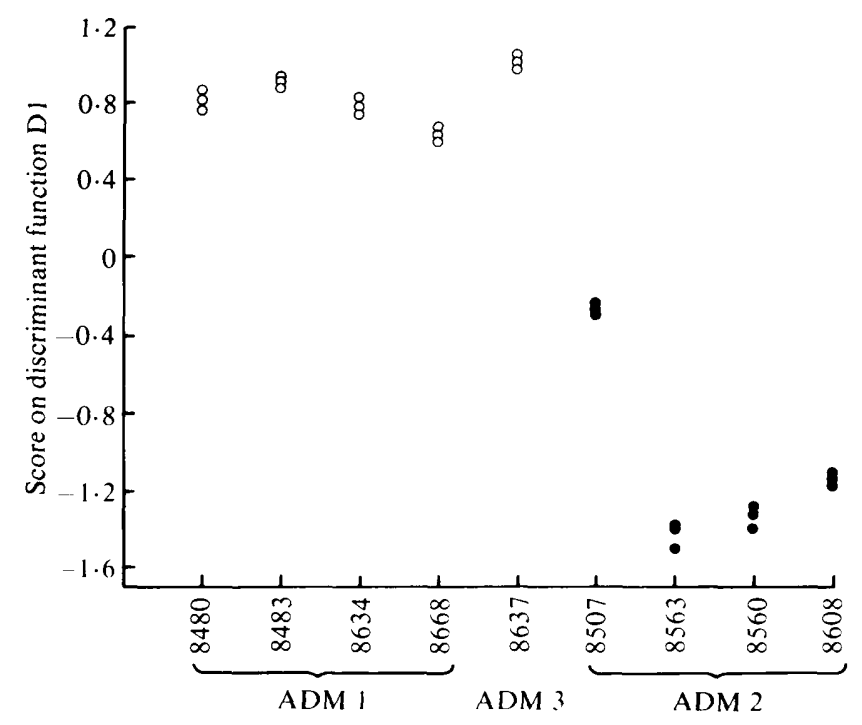

Fig. 1. Characterization of ADM by discriminant analysis of Py-MS data.

combination of the scores on individual discriminant functions in two-dimensional discriminant plots, or non-linear mapping of the scores on all four discriminant functions, indicated that $M$. gordonae, $M$. scrofulaceum and ADM are well separated.

\section{Comparative reciprocal intradermal sensitin (CRIS) testing}

The specificity differences of the pairs of sensitins of the strains are shown in Table 5 . Specificity differences of $<2 \mathrm{~mm}$ were found in the comparisons within three ADM 2 strains $(8251,8563,8608)$ and specificity differences of $>2 \mathrm{~mm}$ in most of the others. Generally, the smaller the differences, the more closely related are the immunogenic structures under study. By means of the criteria for the utilization of the values of specificity differences of sensitins in classification reported previously (Magnusson \& Mariat, 1968), the three ADM 2 strains 8251, 8563 and 8608 belong to one and the same (unknown) species, and ADM 1 strain 8346 belongs to another unknown species. The ADM strains examined are distinct from $M$. avium, $M$. flavescens, $M$. gordonae, $M$. intracellulare, $M$. scrofulaceum and $M$. szulgai, and from the three other unknown species studied. The specificity difference of $2 \mathrm{~mm}$ found in the comparison between ADM 8563 and Mycobacterium sp. MNC 545 is remarkably small, indicating a close relationship between these two strains.

\section{Metabolic studies}

Malate dehydrogenase. NAD-dependent malate dehydrogenase activity was sought in extracts of two ADM strains. In strains 8634 and 8251 , activities of $259 \mathrm{mU}$ (mg protein) ${ }^{-1}$ and $370 \mathrm{mU}$ (mg protein) ${ }^{-1}$, respectively, were detected. Corresponding $R_{F}$ values in polyacrylamide gels were 0.73 and 0.71 . The $R_{F}$ of $M$. leprae malate dehydrogenase in the same gels was 0.63 (see also Wheeler \& Bharadwaj, 1983). ADM and $\boldsymbol{M}$. leprae malate dehydrogenases could be distinguished when $10 \mu \mathrm{g}$ and $25 \mu \mathrm{g}$ protein extracts, respectively, were run in the same gel.

Catabolism of oxygen free radicals. Superoxide dismutase was detected in all four ADM strains tested $(8634,8480,8251$ and 8968$)$. All these strains had an isoenzyme of $R_{F} 0.67-0.69$ in a polyacrylamide gel system in which the $R_{F}$ of $M$. leprae superoxide dismutase was 0.68 (Wheeler \& Gregory, 1980; Wheeler, 1984a). Additionally an isoenzyme of $R_{F} 0 \cdot 35-0.39$ (not present in $M$. leprae) was detected in three (i.e. not 8480) of the four ADM strains studied.

Catalase was sought and detected in two ADM strains (Table 6). This enzyme could not be 
है

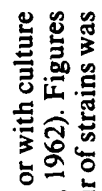

ㄴ.

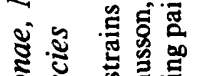

s

¿ $5 \sum^{5} \sum^{2}$

这蓄

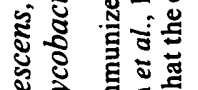

\&

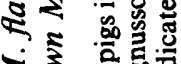

这

2.

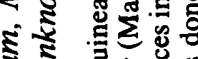

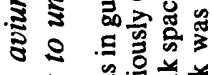

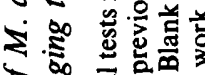

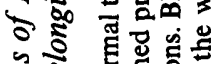

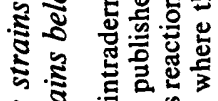

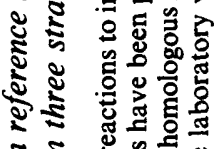

โร

ᄂ

จิ

ป

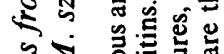

乏

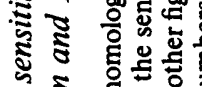

ชิ

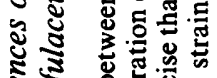

ธิำ

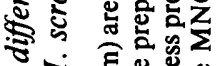

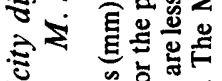

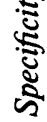

过

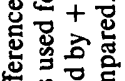

象造

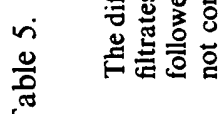

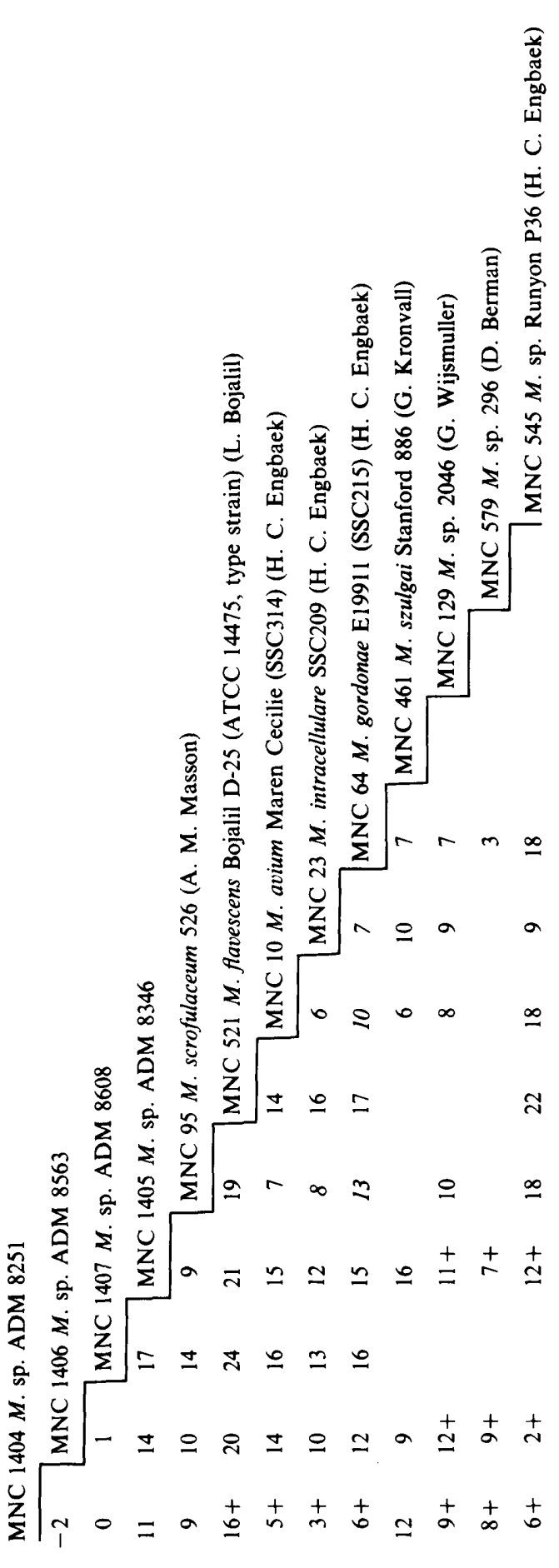


Table 6. Catalase in extracts of $A D M$ and $M$. leprae

The methods, preincubation conditions and units specified in an earlier study of catalase in $M$. leprae (Wheeler \& Gregory, 1980) were used.

\begin{tabular}{|c|c|c|c|c|c|}
\hline \multirow[b]{2}{*}{$\begin{array}{l}\text { Cell-free } \\
\text { extract } \\
\text { from }\end{array}$} & \multicolumn{2}{|c|}{ Enzyme asssay } & \multicolumn{3}{|c|}{ In polyacrylamide gels } \\
\hline & $\begin{array}{c}\text { Specific } \\
\text { activity [mU } \\
\left.(\mathrm{mg} \text { protein })^{-1}\right]\end{array}$ & $\begin{array}{c}\text { Inhibition by } \\
100 \mathrm{mM}-3 \text {-amino- } \\
\text { triazole }\end{array}$ & $R_{F}$ & $\begin{array}{l}\text { Amount of } \\
\text { protein (mg) to } \\
\text { detect activity } \\
\text { on gel }\end{array}$ & $\begin{array}{c}\text { Activity } \\
\text { after } \mathrm{NaOH} \\
(0.5 \mathrm{M}, 30 \mathrm{~min}) \\
\text { treatment }\end{array}$ \\
\hline ADM 8634 & 144 & 65 & $0 \cdot 10,0 \cdot 23$ & 10 & retained \\
\hline ADM 8251 & 48 & 55 & $0.09,0.25$ & 10 & retained \\
\hline M. leprae & $1 \cdot 35$ & 100 & 0.27 & 1000 & abolished \\
\hline
\end{tabular}

detected in $M$. leprae although a host-derived catalase in purified suspensions of $M$. leprae had a very similar $R_{F}$ value to catalase from ADM (Table 6).

\section{Experimental pathogenicity for mice}

None of the seven ADM strains tested multiplied in the mouse foot pads. However, the bacteria remained alive in situ, retrocultures being positive one year after inoculation. After intravenous inoculation, ADM 2, ADM 3, ADM 4 and ADM 5 strains were not pathogenic for mice, while two months after the inoculation, ADM 1 strains produced granulomas in the liver with numerous extracellular acid-fast bacilli.

\section{DNA relatedness}

ADM strains were separated into four groups on the basis of their DNA relatedness (Table 7). Strains 8346, 8480, 8634, 8668 (ADM 1) and 8637 (ADM 3) showed high levels of relatedness $(>90 \%$ ). The second group consisted of strains $8251,8563,8608$ and 8698 (ADM 2), which showed $81-97 \%$ relatedness to each other, but $24-37 \%$ relatedness with the strains of the first group. The third group comprised strain 8837 (ADM 4), which showed about $25 \%$ relatedness with the first and second groups. The fourth group comprised strain 8968 (ADM 5), which showed $34 \%$ homology with ADM 2 strain 8251 , and $23 \%$ with ADM 4 strain 8837 . All ADM strains showed low levels of relatedness $(6-51 \%)$ with selected strains of established species of mycobacteria, although 8837 and 8968 were only hybridized with two mycobacterial DNAs in the present study (M. scrofulaceum P29 and $M$. gordonae ATCC 14470).

\section{DISCUSSION}

The 17 ADM strains formed five homogeneous groups on the basis of cultural, physiological and biochemical properties. Although these strains shared properties with other scotochromogenic mycobacteria, they differed from all other mycobacteria on the basis of the characters listed in Table 2.

The value of mycolic acid analysis in mycobacterial systematics has already been attested (Minnikin \& Goodfellow, 1980; Daffé et al., 1983; Minnikin et al., 1984b, 1985a; Dobson et al., 1985). The patterns reported here emphasize the significance of mycolic acid patterns. Indeed, the patterns of mycolic acid methyl esters recorded for ADM 1 and ADM 2 strains were unusual in showing the presence of $\alpha$-, methoxy-, keto- and dicarboxymycolates; a similar pattern has only been recorded previously for the saprophytic species $M$. komossense (Minnikin et al., $1985 a$ ). The two ADM 3 strains also showed a very unusual mycolic acid pattern, with the absence of $\alpha$-mycolates and the presence of keto- and dicarboxymycolates. The majority of mycobacteria studied so far contain $\alpha$-mycolates (Daffé et al., 1983; Minnikin et al., 1984b; $1985 a, b$ ) but $M$. duvalii strains have minor amounts of $\alpha$-mycolates (Minnikin et al., 1985a). The sizes of the keto- and dicarboxymycolates in ADM 3 strains corresponded to those found in other mycobacteria, confirming that they belong to the genus Mycobacterium. The ADM 1 and ADM 4 strains and the ADM 2 and ADM 5 strains differed in their mycolic acid composition 
Table 7. DNA-DNA relatedness between ADM and other mycobacterial species

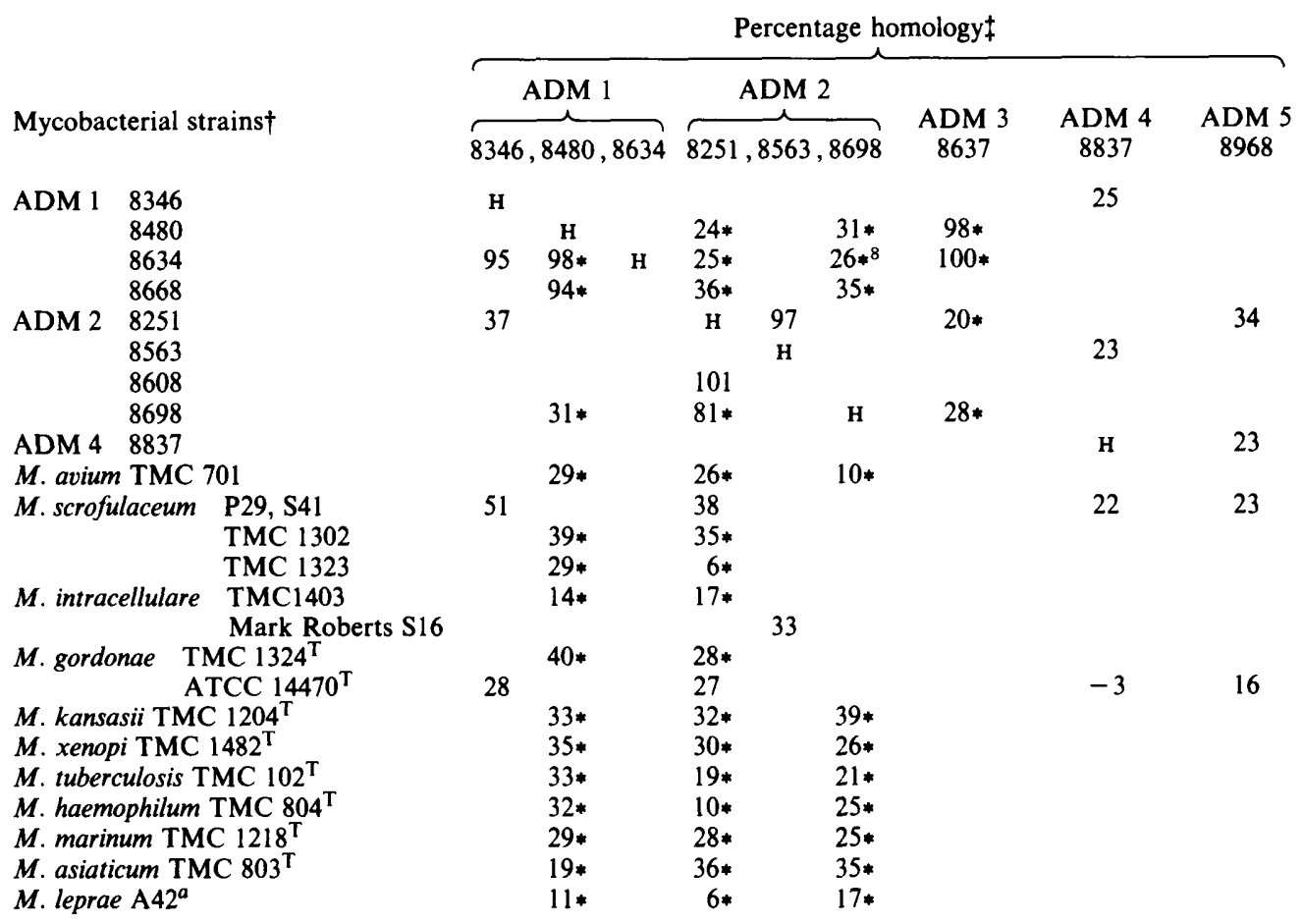

† TMC, Trudeau Mycobacterial Collection; ATCC, American Type Culture Collection; T, type strain; S, serotype. $a$, Strain supplied by E. E. Storrs through the National Institute of Allergy and Infectious Diseases, USA.

†Results marked * are from T. Imaeda's laboratory; others are from I. Baess' laboratory. H, homologous.

(Table 2). Similarly, genomic differences were observed between ADM 1 and ADM 4 strains ( $25 \%$ DNA relatedness) and between ADM 2 and ADM 5 strains ( $34 \%$ DNA relatedness). This again emphasizes the importance of mycolic acids as chemotaxonomic characters.

Polars lipid profiles also confirmed that ADM 1, 2 and 3 strains formed three separate homogeneous groups with lipid patterns that do not coincide with any other mycobacteria known at present.

The mycobactins are useful chemotaxonomic markers for the identification and classification of the mycobacteria (Hall \& Ratledge, 1985; Hall, 1985). By examination of these compounds, ADM 2 strains (8251 and 8563) were readily differentiated from those species previously thought to be closely related, namely $M$. gordonae, $M$. flavescens and mycobacteria belonging to the MAIS complex. By their mycobactin structures, ADM 1 strains (8480 and 8634) and ADM 4 strain 8837 are related to the MAIS complex and ADM 5 strain 8968 seems to differ from the other ADM strains and reference strains tested so far. A recent HPLC study of mycobactins (Hall \& Ratledge, 1985) showed that ADM 1 and 4 strains were indistinguishable from the MAIS group, and that ADM 2 strains synthesize a unique mycobactin different from that of any other species examined.

CRIS testing showed the ADM 2 strains $(8251,8563$ and 8608$)$ to be distinct from the ADM 1 strain 8346 and from $M$. gordonae, M. flavescens, M. szulgai and the mycobacteria of the MAIS complex.

The results of the DNA studies corresponded to those of the phenetic data for all strains except the ADM 3 strain 8637. Although this organism differed from ADM 1 strains in its cultural, physiological and biochemical characters, it showed a high level of DNA relatedness $(98-100 \%)$ with the ADM 1 strains 8480 and 8634 (Table 7). The results obtained by Py-MS 
(Fig. 1), and the presence of mycosides C, also classified 8637 in group ADM 1. However, the difference in the mycolate patterns was mainly quantitative, insofar as the presence of a small amount of $\alpha$-mycolates was demonstrated in strain 8637 . Interestingly, 8637 was isolated from the same armadillo tissue as ADM 1 strains 8346, 8480 and 8483 (Table 1). Strain 8637, like 9091 (ADM 3), was difficult to grow in vitro, causing difficulties in obtaining sufficient bacterial cells for analyses. This could have had some influence on the results of the mycolate determination. It was observed that the fast-growing $M$. duvalii showed a mycolate pattern (different from those of ADM) poor in $\alpha$-mycolate but modified by culture growth conditions. Considering the great discrepancies between the phenotypic and the genomic characteristics, the ADM 3 strains should be studied further. However, discrepancies between genomic and phenotypic characteristics are not unusual and species which differ phenotypically may show high DNA relatedness. This is the case for $M$. tuberculosis and $M$. bovis (Bradley, 1972, 1975; Baess, 1979; Imaeda, 1985), M. avium and M. lepraemurium (Imaeda et al., 1982; Athwal et al., 1984), $M$. scrofulaceum and $M$. xenopi (Imaeda, 1985), and ' $M$. lufu' (Portaels, $1980 a, b$ ) and $M$. asiaticum (Imaeda \& Tsukamura, 1985). Conversely, strains classified in groups ADM 1 and 4 or ADM 2 and 5, which were very similar phenotypically, showed little DNA homology. This was also observed with $M$. avium, $M$. intracellulare and $M$. scrofulaceum, which are combined in a single complex (MAIS) on the basis of phenotypic characters but which show low DNA relatedness among themselves (Baess, 1983; Imaeda \& Tsukamura, 1985). Phenotypically, the ADM strains might be classified into five homogeneous groups, different from all other known mycobacteria. According to DNA studies, these ADM are classified in four homogeneous groups which differ from all other cultivable mycobacterial species mentioned in Table 7.

Both groups ADM 1 and ADM 2 are composed of strains isolated from different animals (Table 1) and should be regarded as representing two novel species of mycobacteria. Since ADM 4 and ADM 5 are each represented by only one strain, more strains of these groups should be analysed before it can be suggested that they might constitute new species of mycobacteria.

Many characters permit differentiation between the ADM strains and $M$. leprae. Firstly, the ADM are cultivable in vitro on conventional media, although some of them require special ingredients (e.g. Ogawa egg yolk medium without malachite green for the ADM 3 strains). Pyridine extraction of acid fastness is not a specific character for the identification of $M$. leprae; indeed, the two ADM 3 strains lost their acid fastness after treatment with fresh pyridine and it has been demonstrated that some other cultivable mycobacteria (M. vaccae, M. phlei) also conform to this test (Dutta et al., 1983). Conversely, the mycolic acid composition clearly differentiates $M$. leprae from the other mycobacterial species and from the ADM. With the exception of some substrains of $M$. bovis BCG (Minnikin et al., 1984b), $M$. leprae is the only species which produces only $\alpha$ - and ketomycolates (Minnikin et al., 1985b). The analysis of glycolipids also differentiated the ADM from $M$. leprae. Moreover, in a recent study (Portaels $e t$ al., 1984), it has been shown that none of the ADM contained the phenolic glycolipid specific to $M$. leprae (Hunter et al., 1982; Minnikin et al., 1985c). Peptidoglycan analyses also differentiated the ADM from $M$. leprae. In $M$. leprae glycine occurs in the peptidoglycan in about the same molar proportion as DAP, while the molar proportion of alanine is less than 1 (Draper, 1976, and unpublished observations). The peptidoglycan of ADM apparently resembles that of other mycobacteria in amino acid composition (Lederer, 1971). It should be noted that 'pure' mycobacterial peptidoglycan should contain about $1 \mu \mathrm{mol}$ DAP $\mathrm{mg}^{-1}$. The material described here contained only $15 \%$ of this amount, largely because, on account of the small quantities obtained, the walls had not been freed from arabinogalactan and mycolic acid. Strain 8511 (ADM 2) contained a molar excess of glutamic acid and ammonia, which would be consistent with the presence of wall-bound, partially amidated polyglutamic acid as described for some other mycobacterial strains (Vilkas \& Markovits, 1972). Further analyses with material less contaminated with non-wall amino acids would be needed to confirm this. The ADM were also distinguished from $M$. leprae on the basis of some enzymes sought during the study of the intermediary metabolism of $M$. leprae (Wheeler, 1984b). The malate dehydrogenases from $M$. leprae, ADM, and armadillo liver have different mobilities in polyacrylamide gels, so any malate dehydrogenase with $R_{F} \neq 0.63$ is likely to be from a source other than $M$. leprae. Catalase in 
ADM was similar in electrophoretic mobility to catalase in armadillo liver, but, in contrast to the liver enzyme, activity could be detected during incubation of ADM catalase with $100 \mathrm{mM}-3-$ aminotriazole. Catalase could not be detected in $\mathrm{NaOH}$-treated $M$. leprae (Wheeler \& Gregory, 1980) so its presence in suspensions of bacteria after treatment with $\mathrm{NaOH}(0.5 \mathrm{M}$, for $30 \mathrm{~min}$, at $25^{\circ} \mathrm{C}$ ) would suggest ADM. Taxonomic studies could be developed by comparing immunological distances (Wayne \& Diaz, 1979) of ADM with each other, and with other mycobacteria. The absence of multiplication of the ADM in mouse foot pads and the low levels of DNA relatedness with $M$. leprae $(6-17 \%)$ also confirmed that they are different from $M$. leprae.

Resulting from this study, it is possible to differentiate the ADM studied from $M$. leprae by cultural, biochemical, metabolic and pathogenic properties. Specific chemical markers, absent in $M$. leprae, have been detected in ADM: there are long-chain alcohols associated with the dicarboxymycolates that may be detected by GC as 2-octadecanol or 2-eicosanol after hydrolysis or methanolysis, or as alkenes by Py-GC of their esters. It has recently been demonstrated that the detection of such markers may be used to check the mycobacterial purity of $M$. leprae preparations. In the $M$. leprae suspensions tested up to now and purified from armadillo tissues using the so-called Protocol 1/79 (World Health Organization, 1980), neither eicosene nor eicosanol was detected (Wieten et al., 1984; Larsson et al., 1985).

If the $M$. leprae-infected armadillo tissues are contaminated by mycobacteria which do not produce dicarboxymycolates and long-chain alcohols (as was recently demonstrated by Portaels et al., 1985), other specific markers should be sought in order to detect all possible types of contamination. In view of this, the use of monoclonal antibodies against $M$. leprae and against cultivable mycobacteria was also recently proposed (Kolk et al., 1985). Enzymic markers, especially dehydrogenases - which are easily visualized after separation on electrophoretic gels - may also be useful to detect contaminants in armadillo tissue. It may be expected that more of these enzymes will be partially characterized (like malate dehydrogenase) in armadillo-grown $M$. leprae as studies on metabolism progress.

Since it is now possible to distinguish $M$. leprae from other mycobacterial species by the features analysed in the present study, any organism cultivated from $M$. leprae-infected tissue should be submitted to similar studies in order to evaluate its degree of relatedness to $M$. leprae and before claiming that it is $M$. leprae.

This work was supported in part by the Damien Foundation, Brussels, and by the Leprosy Unit, World Health Organization, Geneva. We also acknowledge LEPRA (British Leprosy Relief Association) for providing funds for maintaining the colony of infected armadillos. R. M. Hall gratefully acknowledges the support of a grant from the Medical Research Council.

We wish to thank Mrs K. De Ridder, Miss K. Fissette and Miss S. Lathwell for excellent technical assistance. We also thank Mrs Y. Baeten, Miss T. Van Doosselaere and Mrs M. Van Nevele for preparation of the manuscript.

\section{REFERENCES}

Athwal, R. S., Deo, S. S. \& Imaeda, T. (1984). Deoxyribonucleic acid relatedness among $M y c o b a c-$ terium leprae, Mycobacterium lepraemurium and selected bacteria by dot blot and spectrophotometric deoxyribonucleic acid hybridization assays. International Journal of Systematic Bacteriology 34, 371-375.

BAESS, I. (1974). Isolation and purification of deoxyribonucleic acid from mycobacteria. Acta pathologica et microbiologica scandinavica B82, 780-784.

BAEss, I. (1979). Deoxyribonucleic acid relatedness among species of slowly-growing mycobacteria. Acta pathologica et microbiologica scandinavica B87, 221226.

BAEss, I. (1983). Brief report: deoxyribonucleic acid relationships between different serovars of $\mathrm{Myco}$ bacterium avium, Mycobacterium intracellulare and
Mycobacterium scrofulaceum. Acta pathologica, microbiologica et immunologica scandinavica B91, 201-203.

Baess, I. \& Weis Bentzon, M. (1978). Deoxyribonucleic acid hybridization between different species of mycobacteria. Acta pathologica et microbiologica scandinavica B86, 71-76.

Bradley, S. G. (1972). Reassociation of deoxyribonucleic acid from selected mycobacteria with that from Mycobacterium bovis and Mycobacterium farcinica. American Review of Respiratory Diseases 106, $122-124$.

BradLey, S. G. (1975). Significance of nucleic acid hybridization to systematics of actinomycetes. $\boldsymbol{A d}$ vances in Applied Microbiology 19, 59-70.

Convit, J. \& Pinardi, M. E. (1972). A simple method for the differentiation of Mycobacterium leprae from 
other mycobacteria through routine staining technics. International Journal of Leprosy 40, 130-132.

Daffé, M., Lanéelle, M. A., Asselineau, C., LévyFrébault, V. \& DAVID, H. (1983). Intérêt taxonomique des acides gras des mycobactéries: proposition d'une méthode d'analyse. Annales de microbiologie 134B, 241-256.

Dobson, G., Minnikin, D. E., Minnikin, S. M., Parlett, J. H., Goodfellow, M., Ridell, M. \& Magnusson, M. (1985). Systematic analysis of complex mycobacterial lipids. In Chemical Methods in Bacterial Systematics, pp. 237-265. Edited by M. Goodfellow \& D. E. Minnikin. London: Academic Press.

DRAPER, P. (1976). Cell walls of Mycobacterium leprae. International Journal of Leprosy 44, 95-98.

DutTa, A. K., Katoch, V. M. \& Sharma, V. D. (1983). Effect of pyridine extraction on the acid fastness of mycobacteria. Leprosy in India 55, 299-304.

Hall, R. M. (1985). Mycobactins as taxonomic markers for the mycobacteria. Actinomycetes 19 , 92-106.

Hall, R. M. \& Ratledge, C. (1982). A simple method for the production of mycobactin, the lipid-soluble siderophore, from mycobacteria. FEMS Microbiology Letters 15, 133-136.

Hall, R. M. \& Ratledge, C. (1984). Mycobactins as chemotaxonomic characters for some rapidly-growing mycobacteria. Journal of General Microbiology 130, 1883-1892.

Hall, R. M. \& Ratledge, C. (1985). Mycobactins in the classification and identification of armadilloderived mycobacteria. FEMS Microbiology Letters 28, 243-247.

HoOgerbrugge, R., Willig, S. J. \& Kistemaker, P. G. (1983). Discriminant analysis by double stage principal component analysis. Analytical Chemistry 55, 1711-1712.

Hunter, S. W., Fujiwara, T. \& Brennan, P. J (1982). Structure and antigenicity of the major specific glycolipid antigen of Mycobacterium leprae. Journal of Biological Chemistry 257, 15072-15078.

IMAEDA, T. (1985). Deoxyribonucleic acid relatedness among selected strains of Mycobacterium tuberculosis, Mycobacterium bovis BCG, Mycobacterium microti and Mycobacterium africanum. International Journal of Systematic Bacteriology 35, 147-150.

IMAEDA, T. \& TSUKAMURA, M. (1985). Intraspecies and interspecies DNA relatedness among mycobacteria. Proceedings of the Twentieth US-Japan Tuberculosis Research Conference, National Institutes of Health, Bethesda, Maryland 15-16th August, 164-173.

IMAEDA, T., KiRCHHEIMER, W. F. \& BarksDale, L. (1982). DNA isolated from Mycobacterium leprae: genome size, base ratio, and homology with other related bacteria as determined by optical DNADNA reassociation. Journal of Bacteriology 150, 414417.

JENkins, P. A. (1980). Thin-layer chromatography of mycobacterial lipids as an aid to classification. In Mycobakterien und mycobakterielle Krankheiten, Teil 1, Systematik der Mycobakterien, pp. 305-318. Edited by G. Meissner \& R. Pfaffenberg. Jena: Gustav Fischer.

Jenkins, P. A., Pattyn, S. R. \& Portaels, F. (1982). Diagnostic bacteriology. In The Biology of the
Mycobacteria, pp. 441-471. Edited by C. Ratledge \& J. L. Stanford. London: Academic Press.

Kolk, A. H. J., Ho, M. L., KlatSer, P. R., Eggelte, T. A. \& Portaels, F. (1985). Production of monoclonal antibodies against $M$ ycobacterium leprae and armadillo derived mycobacteria. Annales de l'Institut Pasteur/Microbiologie 136B, 217-224.

LARSSON, L., Draper, P. \& PoRTaEls, F. (1985). Use of gas chromatography to differentiate Mycobacterium leprae from cultivable armadillo derived mycobacteria, $\boldsymbol{M}$. avium-intracellulare and $\boldsymbol{M}$. lepraemurium by analysis of secondary alcohols. International Journal of Leprosy 53, 451-457.

LeDERER, E. (1971). The mycobacterial cell wall. Pure and Applied Chemistry 25, 135-165.

Magnusson, M. (1961). Specificity of mycobacterial sensitins. I. Studies in guinea-pigs with purified 'tuberculin' prepared from mammalian and avian tubercle bacilli, Mycobacterium balnei, and other acid-fast bacilli. American Review of Respiratory Diseases 83, 57-68.

MaGnusson, M. (1962). Specificity of sensitins. III. Further studies in guinea-pigs with sensitin of various species of Mycobacterium and Nocardia. American Review of Respiratory Diseases 86, 395-404.

MaGNUSSON, M. (1971). A comparative study of Mycobacterium gastri and Mycobacterium kansasii by delayed type skin reactions in guinea pigs. American Review of Respiratory Diseases 104, 377-384.

Magnusson, M. \& Mariat, F. (1968). Delineation of Nocardia farcinica by delayed type skin reactions on guinea pigs. Journal of General Microbiology 51, 151158 .

Magnusson, M., Engbaek, H. C. \& Bentzon, M. W. (1961). Specificity of mycobacterial sensitins. II. Studies in guinea-pigs with purified sensitin prepared from unclassified acid-fast bacilli. American Review of Respiratory Diseases 83, 69-84.

MinNikin, D. E. \& Goodfellow, M. (1980). Lipid composition in the classification and identification of acid-fast bacteria. In Microbiological Classification and Identification, pp. 189-256. Edited by $\mathbf{M}$. Goodfellow \& R. G. Board. London: Academic Press.

Minnikin, D. E., Minnikin, S. M., O'Donneli, A. G. \& GoODFEllow, M. (1984a). Extraction of mycobacterial mycolic acids and other long-chain compounds by an alkaline methanolysis procedure. Journal of Microbiological Methods 2, 243-249.

Minnikin, D. E., Minnikin, S. M., Parlett, J. H., Goodfellow, M. \& Magnusson, M. (1984b). Mycolic acid patterns of some species of Mycobacterium. Archives of Microbiology 139, 225-231.

Minnikin, D. E., Minnikin, S. M., Parlett, J. H. \& GOODFELLOW, M. (1985a). Mycolic acid pattterns of some rapidly-growing species of Mycobacterium. Zentralblatt für Bakteriologie, Microbiologie und $\mathrm{Hy}$ giene A259, 446-460.

Minnikin, D. E., Dobson, G., Goodfellow, M., Draper, P. \& Magnusson, M. (1985b). Quantitative comparison of the mycolic and fatty acid composition of Mycobacterium leprae and Mycobacterium gordonae. Journal of General Microbiology 131, 2013-2021.

Minnikin, D. E., Dobson, G. \& Draper, P. (1985c). The free lipids of Mycobacterium leprae harvested 
from experimentally infected nine-banded armadillos. Journal of General Microbiology 131, 2007-2011.

PORTAELS, F. (1980a). Unclassified mycobacterial strains susceptible to dapsone isolated from the environment in Central Africa. International Journal of Leprosy 48, 330.

Portakls, F. (1980b). Study of unclassified dapsone sensitive mycobacteria isolated from the environment in Zaïre. Annales de la Société belge de médecine tropicale 60, 381-386.

Portaels, F. \& Pattyn, S. R. (1982). Growth of mycobacteria in relation to the $\mathrm{pH}$ of the medium. Annales de Microbiologie 133B, 213-221.

Portaels, F., Francken, A. \& Pattyn, S. R. (1982). Bacteriological studies of armadillo livers infected with Mycobacterium leprae. Annales de la Société belge de médecine tropicale 62, 233-245.

Portaels, F., Daffé, M., Lanéelle, M. A. \& Asselineau, C. (1984). Etude de la composition lipidique de mycobacteries cultivables isolées de foies de tatous infectés par Mycobacterium leprae. Annales de Microbiologie 135A, 457-465.

Portaels, F., De Ridder, K. \& PATTYN, S. R. (1985) Cultivable mycobacteria isolated from organs of armadillos uninoculated and inoculated with $\mathrm{Myco-}$ bacterium leprae. Annales de l'Institut Pasteur/Microbiologie 136A, 181-190.

RATLEDGe, C. \& Hall, M. J. (1971). Influence of metal ions on the formation of mycobactin and salicylic acid in Mycobacterium smegmatis grown in static culture. Jounal of Bacteriology 108, 312-319.

ShEPARD, C. C. (1960). The experimental disease that follows the injection of human leprosy bacilli into footpads of mice. Journal of Experimental Medicine 112, 445-454.

Tsukamura, M. \& Tsukamura, J. (1966). Differentiation of mycobacteria by utilization of amides and amino acids as sole nitrogen sources. American Review of Respiratory Diseases 94, 104-107.

VILKAS, E. \& Markovits, J. (1972). Sur la présence d'une acide polyglutamique dans les parois de Mycobacterium tuberculosis, souche Peurois. Comptes rendus hebdomadaires de l'Académie des sciences 275c, 913-915.

WAYNE, L. G. \& DiAZ, G. A. (1979). Reciprocal immunological distances of catalase derived from strains of Mycobacterium avium, Mycobacterium tuberculosis and closely related species. International Journal of Systematic Bacteriology 29, 19-25.

WHEELER, P. R. (1984a). Variation of superoxide dismutase levels in extracts of Mycobacterium leprae from armadillo liver. International Journal of Leprosy 52, 49-54.

WHEELER, P. R. (1984b). Metabolism in Mycobacterium leprae: its relation to other research on $M$. leprae and to aspects of metabolism in other mycobacteria and intracellular parasites. International Journal of Leprosy 52, 208-230.

WheEler, P. R. \& Bharadwaj, V. P. (1983). Enzymes of malate oxidation in Mycobacterium leprae grown in armadillo livers. Journal of General Microbiology 129, 2321-2325.

Wieten, G., Haverkamp, J., Groothuis, D. G., Berwald, L. G. \& David, H. L. (1983). Classification and identification of Mycobacterium africanum by pyrolysis mass spectrometry. Journal of General Microbiology 129, 3679-3688.

Wieten, G., Boon, J. J., Groothuis, D. G., Portaels, F. \& Minnikin, D. E. (1984). Rapid detection of mycobacterial contamination in batches of whole cells of purified Mycobacterium leprae by pyrolysis gas chromatography. FEMS Microbiology Letters 25 , 289-293.

WORLD HEALTh ORGanization (1980). UNDP/World Bank/WHO Special Programme for Research and Training in Tropical Diseases. Report of the Fifth Meeting of the Scientific Working Group on the Immunology of Leprosy (IMMLEP). TDR/IMMLEP-SWG (5)/80.3, Annex 4, p. 23. Geneva: WHO. 